\title{
Juvenile xanthogranuloma: a rare benign histiocytic disorder
}

\author{
Aneta Szczerkowska-Dobosz ${ }^{1}$, Dorota Kozicka ${ }^{1}$, Dorota Purzycka-Bohdan ${ }^{1}$, Wojciech Biernat ${ }^{2}$, Marta Stawczyk ${ }^{1}$, \\ Roman Nowicki ${ }^{1}$
}

'Department of Dermatology, Venereology and Allergology, Medical University of Gdansk, Poland Head of Department: Prof. Roman Nowicki MD, PhD

${ }^{2}$ Department of Pathomorphology, Medical University of Gdansk, Poland

Head of Department: Prof. Wojciech Biernat MD, PhD

Postep Derm Alergol 2014; XXXI, 3: 197-200

DOI: 10.5114/pdia.2014.40918

\begin{abstract}
Juvenile xanthogranuloma (JXG) is a rare histiocytic disorder that typically affects children. The clinical presentation of this disease is characterized by single or, rarely, multiple yellow and brown skin nodules, most often found on the face and neck. Internal organ involvement has been sporadically observed in JXG and is associated with an increased risk of serious complications. We report two cases with a small and large nodular form of JXG.
\end{abstract}

Key words: juvenile xanthogranuloma, histiocytosis, nodules, Touton cells.

\section{Introduction}

Juvenile xanthogranuloma (JXG) is a disorder belonging to a group of non-Langerhans cell histiocytoses [1]. This disease typically affects infants and small children. Cutaneous manifestation of JXG includes asymptomatic red and brown papules or nodules, most often with a tinge of yellow. Contrary to other xanthomatous diseases, JXG has not been associated with lipid disturbances or metabolic disorders [2]. In rare cases, it can involve internal organs, which results in serious complications, e.g. blindness as a consequence of glaucoma and bleeding to the anterior chamber of the eye.

We present 2 children with a small and large nodular form of JXG limited to the skin.

\section{Case reports}

\section{Case 1}

An 8-month-old boy was admitted to the Outpatient Department of Dermatology, Venereology and Allergology, Medical University of Gdansk, due to the solitary nodular skin lesion on the chin (Figure 1) and on the fifth finger of the left hand. Domed nodules of a size of a small plum had quite hard consistency, yellowish colour and were painless. In addition, the flat-protruding oval focus of plaque infiltration with a diameter of $2 \mathrm{~cm}$, with a yellow-brownish colour was observed on the skin of the right buttock (Figure 2). The lesions on the skin were first observed at the age of 2 months on the child's chin and in the following 4 to 6 weeks two additional lesions appeared subsequently on the finger and the buttock. The child was examined by a dermatologist, who clinically diagnosed xanthomas and recommended observation. On admission neither lymph node enlargement nor hepatosplenomegaly was observed in the physical examination. The mucous membranes were not affected. The child was delivered naturally in the $37^{\text {th }}$ week of pregnancy with 10 points in Apgar score and birth weight of $2700 \mathrm{~g}$ (third pregnancy and second childbirth). The baby was hospitalized in the paediatric ward three times due to the respiratory and urinary tract infections (in the $5^{\text {th }}$ and $8^{\text {th }}$ week of life and $4^{\text {th }}$ month of life).

Microscopic examination of the tissue sample of the skin lesion from the buttock has confirmed a clinical suspicion of JXG and showed monotonous infiltration of the skin consisting of mononuclear histiocytes with the following phenotype: CD68(+), CD1a(-), CD43(+ focally), S100(-), CD117(-), SMA(-), desmin(-), tryptase(-), vimentin(-), Ki67 index $<2 \%$. No epidermotropism was identified. Scattered single eosinophils and multinucleated cells were present among histiocytes. Despite the lack of Touton cells in the microscopic section, which are

Address for correspondence: Aneta Szczerkowska-Dobosz MD, PhD, Department of Dermatology, Venereology and Allergology, Medical University of Gdansk, 7 Debinki St, 80-211 Gdansk, Poland, phone: +48 509093 699, e-mail: adobosz@gumed.edu.pl Received: 21.04.2013, accepted: 23.05.2013. 


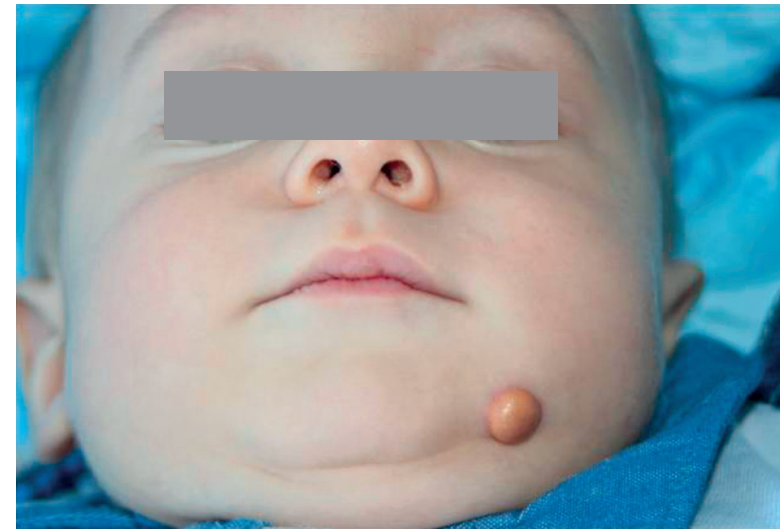

Figure 1. Case 1. Yellowish nodular lesion of the chin

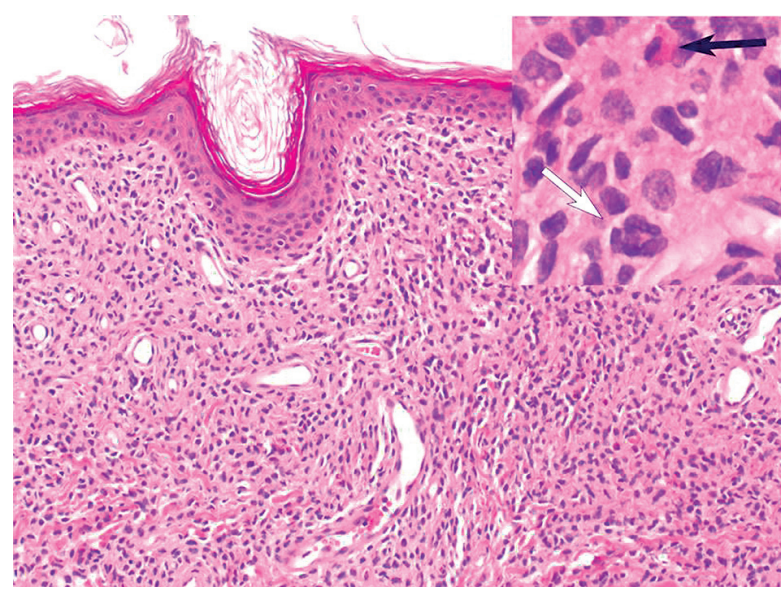

Figure 3. Case 1. Cutaneous infiltrate of histiocytes sparing the epidermis. Note the presence of single multinucleated cell (white arrow) and eosinophils (black arrow) among the histiocytes

typical for this disease, an early form of JXG was diagnosed (Figure 3).

There was no deviation from the normal state in an abdominal ultrasound examination and chest radiography. The ophthalmic examination excluded changes in the sight organ. The child is being regularly monitored by the dermatologist, paediatrician and ophthalmologist.

\section{Case 2}

A 19-month-old girl was referred to the Outpatient Department of Dermatology, Venereology and Allergology, Medical University of Gdansk, with two small fitted tight nodules on the side of the fourth toe of the right foot measuring $3 \mathrm{~mm}$ and $2 \mathrm{~mm}$ in diameter, respectively (Figure 4). These changes were flesh-coloured and painless. For the first time skin lesions appeared on the child's skin at the age of twelve months and were diagnosed by a paediatrician as viral warts and were treat-

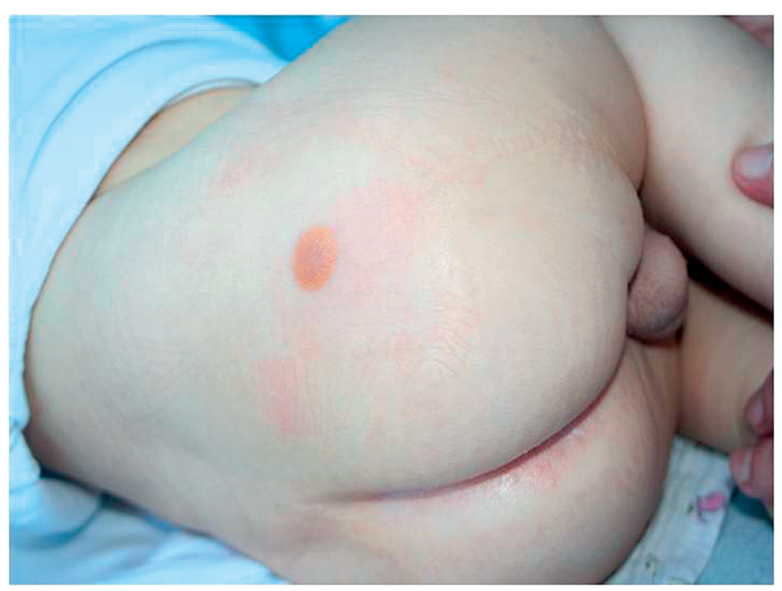

Figure 2. Case 1. Uncommon clinical presentation of cutaneous JXG - plaque-like lesion on the buttock

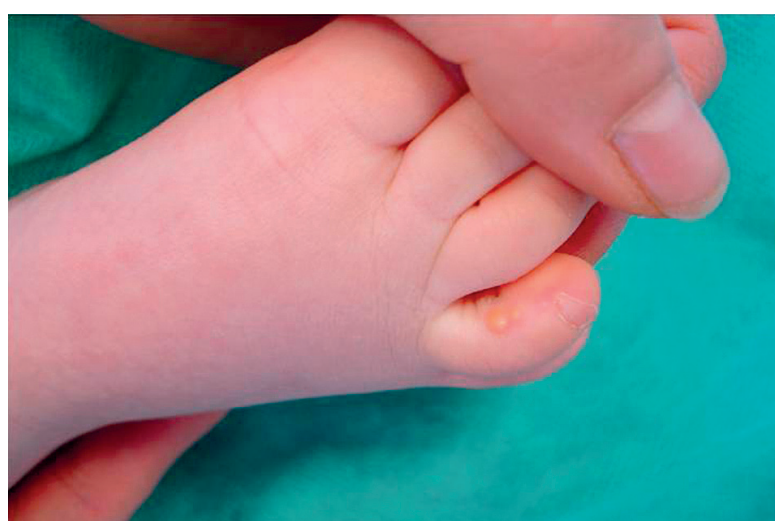

Figure 4. Case 2. Small fitted tight nodules on the side of the fourth toe of the right foot

ed with local antiviral medicaments. This therapy was, however, not effective. As a result of the next consultation, molluscum contagiosum has been diagnosed. There were no other known medical problems. The child was delivered naturally at 38 weeks with 10 points in Apgar score and birth weight of $3300 \mathrm{~g}$ (first pregnancy and first childbirth).

Histopathological examination of the skin nodule confirmed the diagnosis of JXG (Figure 5). Changes in the internal organs were excluded based on additional examinations such as: chest RTG, abdominal USG and ophthalmologist and paediatrician consultation.

\section{Discussion}

Juvenile xanthogranuloma is the most common type of histiocytosis deriving from non-Langerhans cells (non-Langerhans cell histiocytosis). Although, the term 


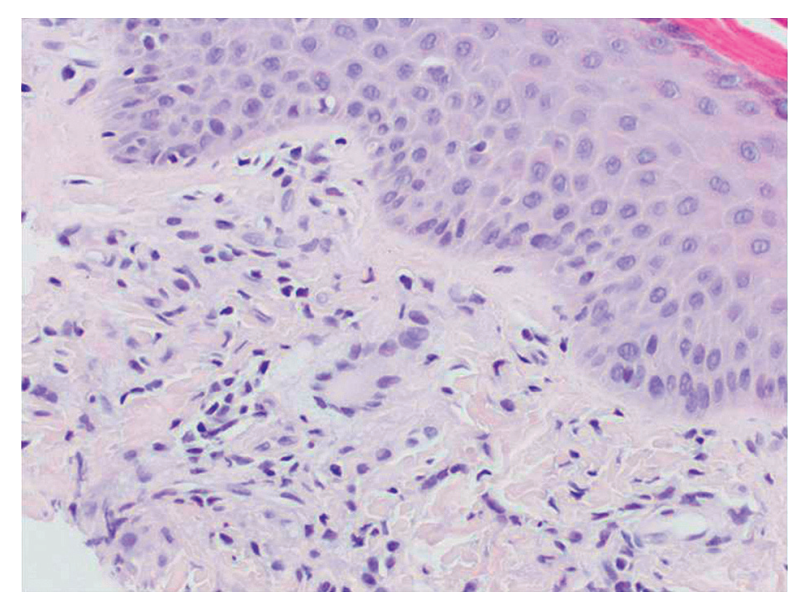

Figure 5. Case 2. Superficial skin biopsy reveals typical appearance of JXG with Touton cell present

was coined by Helwig and Hackney in 1954 [3], the original description of this entity came from Adamson who described it five decades earlier as "congenital xanthoma multiplex" [4].

In $40-70 \%$ of patients, JXG develops in the first year of life [5]. In 5-17\% of cases, the skin lesions may appear soon after birth [3, 5]. The highest incidence of JXG in adulthood is observed in patients aged 20 to 30 years, but the disease is generally rare in adults. In both our cas$\mathrm{es}$, the skin lesions developed in the second and twelfth month of life, respectively. The disease most often affects male children, whereas in adults, there is no sex prevalence [5-8]. The aetiology of this disease remains unknown. Most authors presume that JXG is caused by granulomatous histiocytic reaction in response to undetermined stimuli, probably physical or infectious [9-12]. Bergman et al. revealed that in monocyte-derived macrophages of adult patients with JXG, intracellular synthesis of cholesterol is enhanced. Because dermal macrophages are derived from blood monocytes, it is presumed that this process may be responsible for cholesterol accumulation in JXG skin lesions [13].

Skin manifestations in JXG include well-separated nodules of different size and colour, usually yellow or red-brown, measuring up to $1 \mathrm{~cm}$ in most cases. Rarely, as presented in one of our cases, JXG may present as plaque-like lesions [1]. Nodules may be single (60-82\% of patients) or multiple and most typically are located on the head, neck and upper trunk, but lesions may affect any site of the body, whereas mucosal lesions associated with JXG are hardly ever observed [5, 14, 15]. Gianotti described two most frequent clinical types of JXG [16]. A small nodular form with nodules that are well separated from the surrounding skin and measuring from $2 \mathrm{~mm}$ to $5 \mathrm{~mm}$. Nodules in the large nodular form can reach the size of 1-2 cm. Both types of the disease may coexist in the same patient [16]. Uncommon manifestations of JXG include the giant form with lesions up to $10 \mathrm{~cm}$ in size, the distorting face type called Cyrano type and lichenoid JXG $[9,17,18]$. A solitary tumour located subcutaneously or deep in soft tissues may be another clinical presentation of JXG. Similarly to multifocal cutaneous lesions they affect children in the first month of life [1].

The disease sporadically affects internal organs, which is predominantly observed in patients with multiple skin nodules [19]. Intraocular complications are detected in less than $0.5 \%$ of patients with cutaneous JXG. Noteworthy, about $92 \%$ of these patients were children aged 2 years or younger. Late-recognized secondary glaucoma and bleeding to the anterior chamber of the eye in the course of JXG are serious complications, which may cause blindness [19]. Juvenile xanthogranuloma may also involve the internal organs, e.g. lungs, liver, central nervous system, bones and endocrine glands with different systemic symptoms [3, 20-24].

The correlation of JXG with neurofibromatosis type I and with myelomonocytic leukaemia has been well documented [25-28]. There are limited reports about coexistence of JXG with Niemann-Pick disease, urticaria pigmentosa and cytomegalovirus infection [12, 29, 30].

The diagnosis of JXG is usually not difficult. Nevertheless due to its rarity, the knowledge of this disease among physicians, as revealed by anamnesis of both our cases, remains unsatisfactory. Skin lesions may be erroneously diagnosed as Langerhans cell histiocytosis ("histiocytoses X"), Spitz nevus, urticaria pigmentosa, pyogenic granuloma and also, as in our cases, xanthomas and molluscum contagiosum [31]. Histopathological examination of the skin biopsy is decisive in such cases. In doubtful cases, an immunohistochemical staining should be performed. Typical morphological presentation includes diffuse infiltration of the skin by histiocytes, multinucleated giant cells, with Touton cells, and foam cells admixed with lymphocytes and granulocytes, notably eosinophils. Foam cells can be distinguished by vacuolated cytoplasm and small round centrally located nucleus. Multinucleated giant cells (Touton cells) are observed in $85 \%$ of JXG cases [1]. They have a ring of nuclei around high lipid content cytoplasm. In chronic lesions, fibrosis may occur [32]. Immunohistochemical staining plays a key role in diagnosis of atypical cases of JXG. Macrophage markers, especially CD68, factor XIIIa and vimentin are positive [6, 33]. In some cases, an expression of protein $\mathrm{S} 100$ can be found, whereas CD1a is usually negative $[1,34]$.

The prognosis in patients with JXG without internal organ involvement is favourable. Spontaneous regression usually occurs within 6 months to 3 years $[5,35]$. Recurrence of JXG has been rarely reported. Cosmetic reasons are the main indication for surgical removal of nodules. Surgery is also indicated in patients with long-lasting skin lesions of large size. The management of extra-cutaneous JXG is more difficult. Chemotherapy, radiotherapy, immunosuppression (steroids, cyclosporine, methotrex- 
ate) or surgery can be used in monotherapy or in combination with various clinical effects [17, 20].

\section{Conclusions}

Juvenile xanthogranuloma is the most common benign type of histiocytosis in children. Skin lesions, especially single, are frequently underdiagnosed and, due to the lack of symptoms, neglected by physicians. Nevertheless, because of the low, but potentially serious, risk of internal organ involvement it is pivotal to know the signs and symptoms of this rare disease.

\section{Conflict of interest}

None declared.

\section{References}

1. Dehner LP. Juvenile xanthogranulomas in the first two decades of life: a clinicopathologic study of 174 cases with cutaneous and extracutaneous manifestations. Am J Surg Pathol 2003; 27: 579-93.

2. Zaremba J, Zaczkiewicz A, Placek W. Eruptive xanthomas. Postep Derm Alergol 2013; 30: 399-402.

3. Helwig EB, Hackney VC. Juvenile xanthogranuloma (nevo-xanthoendothelioma). Am J Pathol 1954; 30: 625-6.

4. Adamson NF. Congenital xanthoma multiplex in a child. $\mathrm{Br}$ J Dermatol 1905; 17: 222-3.

5. Cohen BA, Hood A. Xanthogranuloma: report on clinical and histological findings in 64 patients. Pediatr Dermatol 1989; 6: 262-6.

6. Marrogi AJ, Dehner LP, Coffin CM, et al. Benign cutaneous histiocytic tumors in childhood and adolescence, excluding Langerhans' cell proliferations. A clinicopathologic and immunohistochemical analysis. Am J Dermatopathol 1992; 14: 8-18.

7. Zvulunov A, Barak Y, Metzker A. Juvenile xanthogranuloma, neurofibromatosis, and juvenile chronic myelogenous leukemia. World statistical analysis. Arch Dermatol 1995; 131: 904-8.

8. Rodriguez J, Ackerman AB. Xanthogranuloma in adults. Arch Dermatol 1976; 112: 43-4.

9. Seo IS, Min KW, Mirkin LD. Juvenile xanthogranuloma. UItrastructural and immunocytochemical studies. Arch Pathol Lab Med 1986; 110: 911-5.

10. Esterly NB, Sahihi T, Medenica M. Juvenile xanthogranuloma. An atypical case with study of ultrastructure. Arch Dermatol 1972; 105: 99-102.

11. Matsuzaki A, Yo S, Isayama T. Juvenile xanthogranuloma of the hand. J Hand Surg Br 1984; 9: 341-2.

12. Balfour HH, Speicher CE, McReynolds DG, et al. Juvenile xanthogranuloma associated with cytomegalovirus infection. Am J Med 1971; 50: 380-4.

13. Bergman R, Aviram M, Shemer A, et al. Enhanced low-density lipoprotein degradation and cholesterol synthesis in monocyte-derived macrophages of patients with adult xanthogranulomatosis. J Invest Dermatol 1993; 101: 880-2.

14. Takeda Y, Suzuki A, Fujioka Y, et al. Xanthogranuloma of the oral cavity in adult. A case report and review of the literature. Acta Pathol Jpn 1986; 36: 1565-70.

15. Satow SJ, Zee S, Dawson KH, et al. Juvenile xanthogranuloma of the tongue. J Am Acad Dermatol 1995; 33: 376-9.
16. Gianotti F. Cutaneous proliferative histiocytosis in children. G Ital Dermatol Venereol 1980; 115: 101-5.

17. Caputo R, Grimalt R, Gelmetti C, et al. Unusual aspects of juvenile xanthogranuloma. J Am Acad Dermatol 1993; 29: 868-70.

18. Torrelo A, Juarez A, Hernandez A, et al. Multiple lichenoid juvenile xanthogranuloma. Pediatr Dermatol 2009; 26: 238-40.

19. Chang MW, Frieden IJ, Good W. The risk intraocular juvenile xanthogranuloma: survey of current practices and assessment of risk. J Am Acad Dermatol 1996; 34: 445-9.

20. Freyer DR, Kennedy R, Bostrom BC, et al. Juvenile xanthogranuloma: form of systemic disease and their clinical implications. J Pediatr 1996; 129: 227-37.

21. Garcia-Peńa P, Mariscal A, Abellan C, et al. Juvenile xanthogranuloma with extracutaneous lesions. Pediatr Radiol 1992; 22: 377-8.

22. Diard F, Cadier L, Billaud C, et al. Neonatal juvenile xanthogranulomatosis with pulmonary, extrapleural and hepatic involvement. One case report. Ann Radiol 1982; 25: 113-8.

23. Guthrie JA, Arthur RJ. Juvenile xanthogranuloma with pulmonary, subcutaneous and hepatic involvement. Clin Radiol 1994; 49: 498-500.

24. Botella-Estrada R, Sanmartín O, Grau M, et al. Juvenile xanthogranuloma with central nervous system involvement. Pediatr Dermatol 1993; 10: 64-8.

25. Jensen NE, Sabharwal S, Walker AE. Naevoxanthoendothelioma and neurofibromatosis. Br J Dermatol 1971; 85: 326-30.

26. Newell GB, Stone OJ, Mullins JF. Juvenile xanthogranuloma and neurofibromatosis. Arch Dermatol 1973; 107: 262.

27. Nazzaro V, Blanchot-Bardon C, Petit D, et al. Xanthogranuloma juvenile et maladie de Recklinghausen. Ann Dermatol Venereol 1987; 114: 1434-6.

28. Leverger G, Schaison G, Boiron M. Acute myelomonocytic leukemias in children with xanthomas. Xantholeukemia. Arch Fr Pediatr 1984; 41: 179-84.

29. Sibulkin D, Olichney JJ. Juvenile xanthogranuloma in a patient with Niemann-Pick disease. Arch Dermatol 1973; 108: 829-31.

30. De Villez RL, Limmer BL. Juvenile xanthogranuloma and urticaria pigmentosa. Arch Dermatol 1975; 111: 365-6.

31. Iwuagwu FC, Rigby HS, Payne F, et al. Juvenile xanthogranuloma variant: a clinicopathological case report and review of the literature. Br J Plast Surg 1999; 52: 591-3.

32. McKee PH. Atlas of skin pathology [Polish]. Urban and Partner, Wrocław 2003; 214.

33. Misery L, Larbre B, Lyonnet S, et al. Remission of Langerhans cell histiocytosis with thalidomide treatment. Clin Exp Dermatol 1993; 18: 487.

34. Zelger B, Cerio R, Orchard G, et al. Juvenile and adult xanthogranuloma. A histological and immunohistochemical comparison. Am J Surg Pathol 1994; 18: 126-35.

35. Roper SS, Spraker MK. Cutaneous histiocytosis syndromes. Pediatr Dermatol 1985; 3: 19-30. 